\title{
LA COBERTURA SOCIAL DE LOS TRABAJADORES AUTÓNOMOS ORDINARIOS CUANDO SE PRODUCE EL CESE DE SU ACTIVIDAD EN EL ORDENAMIENTO JURÍDICO ESPAÑOL
}

["The Social Security Coverage in the Spanish Legal System of Ordinary SelfEmployed Workers Upon Cessation of Their Activities"]

\author{
María José Cervilla Garzón* \\ Universidad de Cádiz, España
}

\begin{abstract}
RESUMEN
En los países europeos, la mayor diferencia en la protección social dispensada a los trabajadores autónomos frente a la establecida para los trabajadores asalariados se encuentra en la ausencia de cobertura social cuando cesan en su actividad profesional. Este estudio tiene como objetivo analizar los aspectos más significativos de la reciente regulación en el ordenamiento jurídico español de la denominada "prestación por cese de actividad" para los trabajadores autónomos, a través de la Ley $\mathrm{N}^{\mathrm{a}}$ $32 / 2010$, de 5 de agosto, muy novedosa y sin referentes en el Derecho comparado europeo, con la que se pretende acabar con esta desigualdad.
\end{abstract}

Palabras clave

Trabajadores autónomos - Protección social - Cese de actividad.

\section{Abstract}

In European countries, the most important difference in the social protection given to the self-employed workers, in terms of the protection given to the wage-earning employee, is the lack of social coverage when they cease their professional activity. This article is aimed at analyzing the most important aspects of the recent regulation in the Spanish legal system called "benefits over cessation of activities" for self-employed workers, by way of Act No. 32/2010, of 5 August, extremely innovative and without any points of reference to the comparative European Law, which aims at putting an end to this inequality.

\section{KEYWORDS}

Self-employed employees - Social protection - Cessation of activity.

Recibido el 10 de abril y ACEPTADo el 22 de mayo de 2012.

* Profesora colaboradora del Departamento de Derecho del Trabajo y de la Seguridad Social de la Universidad de Cádiz. Dirección postal: Comandante Paz Varela, 8, $3^{\circ}$ A, 11405 Jerez de la Frontera, Cádiz, España. Correo electrónico: mariajose.cervilla@ uca.es 


\section{INTRODUCCIÓN**}

La primera cuestión que debemos abordar en el presente estudio, por las diferencias que entre unos y otros países puedan estar establecidas, es la relativa a la delimitación conceptual de lo que entendemos, a nuestros efectos, por "trabajadores autónomos". En relación al uso de esta terminología, es de destacar la amplia diversidad de denominaciones que son utilizadas para referirse a él ${ }^{1}$, siendo las más frecuentes las de trabajador por cuenta propia, autónomo, no asalariado, no dependiente e independiente ${ }^{2}$. Si bien es cierto que, en ocasiones, son utilizados como términos sinónimos, otras veces se establecen matices de diferencia entre ellos ${ }^{3}$.

** Abreviaturas utilizadas: LETA.. = Ley No 20/2007, de 11 de julio: Reguladora del Estatuto del Trabajo Autónomo; RETA.. = Régimen Especial de Trabajadores Autónomos, regulado por el Decreto No 2530/1970, de 20 de agosto.

${ }^{1}$ Destacado por López Aniorte, María del Carmen Ámbito subjetivo del Régimen Especial de Trabajadores Autónomos (Pamplona, Aranzadi, 1996), pp. 34, que pone de manifiesto la dificultad de encontrar una noción común.

${ }^{2}$ Sin pretender ser exhaustivos debido al gran número de normas, informes y documentos en los que se alude a esta forma de trabajo, podemos poner algunos ejemplos de esta diversidad conceptual, tanto a nivel interno como a nivel internacional. En el ámbito de la Unión Europea, sirvan como ejemplo el artículo 43 del Tratado Constitutivo de la Comunidad Económica Europea, en el que se establece que "La libertad de establecimiento comprenderá el acceso a las actividades no asalariadas”, el Reglamento No 1408/1971, relativo a la aplicación de los Regímenes de Seguridad Social a los trabajadores por cuenta ajena, a los "trabajadores por cuenta propia" y a sus familias que se desplazan dentro de la Comunidad y la Directiva No 86/613/ CEE, del Consejo, de 11 de noviembre, relativa a la aplicación del principio de igualdad de trato entre hombres y mujeres que ejerzan una actividad "autónoma" (bien es cierto que en distintas normas de la Unión Europea el concepto de trabajador se remite a la normativa propia de los Estados Miembros, como ejemplo de ello, artículo 2.2 Directiva No 96/71/CE del Parlamento Europeo y del Consejo, de 16 de diciembre de 1996, sobre el desplazamiento de los trabajadores efectuado en el marco de una prestación de servicios). En el marco de la Organización Internacional del Trabajo, en la Resolución sobre la Clasificación Internacional de la Situación en el Empleo (CISE), adoptada en la decimoquinta Conferencia Internacional de Estadísticos del Trabajo celebrada en Ginebra el 28 de enero de 1993, la distinción que se realiza es entre empleo asalariado-empleo independiente. La Convención internacional sobre la protección de los derechos de todos los trabajadores migratorios y de sus familiares, adoptado por la Asamblea General del Alto Comisionado de las Naciones Unidas para los Derechos Humanos en su Resolución No 45/158, de 18 de diciembre de 1990, se refiere a ellos como trabajadores por cuenta propia. En nuestro propio ordenamiento jurídico-laboral, el artículo 3.1 de la Ley orgánica de libertad sindical los cita como trabajadores por cuenta propia, y la Ley de prevención de riesgos laborales, articulos 3.1 y 24.4, como trabajadores autónomos.

${ }^{3}$ Esto se produce, fundamentalmente, cuando el trabajo autónomo se aborda desde 
Actualmente, en el ámbito de nuestro ordenamiento jurídico es irrelevante la utilización de uno u otro de los mencionados ${ }^{4}$. Buena prueba de ello la encontramos en el contenido de sus normas específicas, que no efectúan ningún tipo de distinción entre los términos trabajador por cuenta propia y autónomo 5 . Sí es cierto que hay determinadas denominaciones, como la de empleo independiente o no dependiente, que las normas españolas han sido más reticente a utilizar, probablemente por la designación que posee el único Régimen de Seguridad Social que es de exclusiva aplicación a esta forma de trabajo, cual es el Régimen Especial de Trabajadores por Cuenta Propia o Autónomos (= RETA.) $)^{6}$. Pero lo cierto es que esta simplificación en su tratamiento no coincide con la existencia de una única forma de prestar servicios profesionales, sino que entre sus fronteras queda incluida una realidad compleja, cuyos contornos pueden ser delimitados desde ordenamientos jurídicos muy diversos (civil, administrativo o mercantil) y a las que es difícil ofrecer una definición común. Es más, "a priori” se puede establecer que el trabajo autónomo es una "forma de empleo que agrupa a

la perspectiva de su fomento o del razonamiento puramente jurídico-laboral. Sucede en materia de fomento del empleo autónomo porque generalmente estas políticas se centran en determinadas categorías de ellos y no en todos, por lo que se suelen ofrecer conceptos parciales al estilo del que aparece en Promoción del empleo por cuenta propia, Informe VII, Conferencia Internacional del Trabajo, $77^{\mathrm{a}}$ reunión, Oficina Internacional del Trabajo, Ginebra 1990, pp. 1, en el que se dice que cabe definir al trabajo por cuenta propia como "trabajadores autónomos y empleadores" (excluyéndose así del alcance de este término a otras posibles categorías como los profesionales liberales o los socios de sociedades cooperativas). Por otra parte, también se diferencia entre trabajo por cuenta propia y trabajo autónomo cuando se entiende que cada una de estas expresiones destacan una parte de las notas que caracterizan a esta forma de trabajo y que, por lo tanto, su significado no es igual. Así: MARTín VALVERde, Antonio, Trabajo asalariado y trabajo autónomo en el derecho comunitario europeo, en AA.VV Trabajo subordinado y trabajo autónomo en la delimitación de fronteras del Derecho del Trabajo (Madrid, Tecnos, 1999), p. 93, dice que, desde el punto de vista dogmático, la clasificación que distingue entre trabajo por cuenta propia y trabajo autónomo no es exactamente coincidente, pues atiende la primera al criterio de la atribución del resultado y al segunda al criterio del modo de ejecución del trabajo. En ello también insiste BALlester PAstor, Inmaculada El trabajador autónomo de la industria y de los servicios en el ordenamiento jurídico de la Seguridad Social en Revista de Trabajo y Seguridad Social, 17 (1995), p. 35.

${ }^{4}$ Opción también aceptada por López Aniorte, María del Carmen, cit. (n. 1), p. 41 .

${ }^{5}$ Con anterioridad a la configuración del Sistema de Seguridad Social, la asimilación se producía entre el "trabajo independiente o autónomo", en el Decreto de 23 de Junio de 1960 por el que se les integra en el Mutualismo Laboral, artículo 1.

${ }^{6}$ Regulado por Decreto No 2.530/1970, de 20 de agosto y Orden de 24 de septiembre de 1970. 
otras formas de empleo"7. Basta con citar la distinta configuración jurídica de los trabajos efectuados bajo formas societarias civiles o mercantiles, en régimen de cooperativa, como empleador con trabajadores a su cargo, como empresario sin trabajadores a cargo, como autónomo individual, como familiar del empresario, como titular de un establecimiento abierto al público o como profesional liberal.

Antes de la aprobación del Estatuto del Trabajo Autónomo (= LETA. $)^{8}$, actual norma de referencia en España en lo que a la determinación de los derechos profesionales de los trabajadores autónomos se refiere, la única referencia explícita a esta cuestión se ubicaba en las normas del RETA., al establecer que "se entenderá como trabajador por cuenta propia o autónomo aquel que realiza [...] una actividad económica [...] sin sujeción por ella a contrato de trabajo [...]" $]$. Es decir, este Régimen no optaba por decir "lo que es" el trabajador por cuenta propia, sino "lo que no es", acudiendo a lo que se conoce como definición "en negativo" o "por exclusión" ${ }^{10}$. Se consideraba, por lo tanto, como trabajo autónomo, al que no cumplía con los requerimientos exigidos por el artículo 1.1 del Estatuto de los Trabajadores para ser considerado trabajador asalariado, fundamentalmente ajenidad, dependencia y retribución en el desarrollo de su relación profesional ${ }^{11}$.

${ }^{7}$ Promoción del empleo por cuenta propia, cit. (n. 3), pp. 78.

${ }^{8}$ Ley No 20/2007, de 11 de julio.

${ }^{9}$ Artículos 2.1 y 1.1 normas citadas en nota 6.

${ }^{10}$ En innumerables ocasiones la doctrina hace referencia a tales términos, por todos: Alarcón Caracuel, Manuel Ramón - González Ortega, Santiago, Compendio de Seguridad Social (4a edición renovada, Madrid, Tecnos, 1991), p. 328; BALlester Pastor, Inmaculada, cit. (n. 3), p. 29; y López Aniorte, M. C., cit. (n. 1), p. 40.

${ }^{11}$ Numerosísimas resoluciones del Tribunal Supremo realizan esta afirmación, entre ellas, las de 29 de diciembre de 1999 (Ar: 1427), 12 de abril de 1996 (Ar: 3075), 10 de abril de 1995 (Ar: 6784), 7 de abril de 1994 (Ar: 2210), 14 de febrero de 1994 (Ar: 1035) y 27 de mayo de 1992 (Ar: 3678). Sobre la doctrina del Tribunal Supremo con relación a las notas que configuran la laboralidad, véase: LuJÁN AlCARÁz, Juan, Las notas de laboralidad. Una aproximación en clave de jurisprudencia en Aranzadi Social, 16 (diciembre 2000). Según el estudio de Martín Valverde, Antonio, cit. (n. 3), p. 83, en la generalidad de los países de este ámbito la definición del trabajador por cuenta propia también suele estar referida a las notas que caracterizan el contrato de trabajo y éstas coinciden bastante con las nuestras. Desde luego, así ocurre en el ordenamiento jurídico francés y en el italiano. Con relación al primero: JAVILliER, Jean-Claude, Droit du travail (2a edición, Paris, Librairie Generale de Droit et Jurisprudence, 1981), p. 73, define la prestación de servicios asalariada como "[...] une personne (le salarié) s'engage á travallier sous la subordination juridique d'une autre (l'employeur) qui la rémunére". Del Giudice, F. - Mariani, F. - Izzo, F. Diritto del lavoro (18 a edición, Napoli, Edizioni Giuridiche Simone, 2000), p. 49, establecen que el trabajador subordinado "[...] si obliga medianti retribuzione a collaborare nell'impresa, prestando il 
La promulgación de la LETA. conlleva dos cambios significativos. Por una parte, se incluye una definición específica de lo que debe ser considerado como trabajador autónomo: "personas físicas que realicen de forma habitual, personal y directa, por cuenta propia y fuera del ámbito de dirección y organización de otra persona, una actividad económica o profesional a titulo lucrativo, de o no ocupación a trabajadores por cuenta ajena"12. Expresamente excluidos de esta consideración van a ser las relaciones laborales protegidas por el Estatuto de los Trabajadores (por lo que sigue siendo válida la definición "por exclusión", son autónomos aquellos a los que no son aplicables los requisitos del artículo 1,1) y la actividad que se limita simplemente al mero desempeño de cargos de consejeros o miembros del consejo de administración de empresas que revisten forma jurídica societaria, así como a determinados familiares del empresario ${ }^{13}$. Por otra parte, se regula una nueva forma de empleo, que comparte características propias de las prestaciones de servicios autónomas y asalariadas, a la que se denomina "autónomos económicamente dependientes" 14 , que tiene un régimen jurídico específico y diferenciado respecto al establecido para el autónomo ordinario en determinadas materias. En términos generales, se consideran autónomos económicamente dependientes a aquellos que realizan una actividad predominante para un cliente por percibir, al menos, el $75 \%$ de sus ingresos de él, siempre y cuando cumpla con una serie de condiciones como el no tener trabajadores a su cargo,

proprio lavoro intellettuale o manuale alle dipendenze e sotto la direzione dell' imprenditore". Omitimos la referencia a la voluntariedad, puesto que no nos parece un elemento delimitador del contrato de trabajo, sino uno de los presupuestos definitorios de los contratos en general, integrado dentro del "consentimiento contractual" y que, por lo tanto, es del todo irrelevante su alusión como factor de expulsión del ámbito de la laboralidad. En este sentido, LuJán AlCARÁz, Juan La contratación privada de servicios y el contrato de trabajo (Madrid, Ministerio de Trabajo y Seguridad Social, 1994), p. 207, pone de manifiesto lo innecesario de su inclusión en el precepto en relación al cual manifiesta que “[...] se explica, en realidad, más como atadura a la tradición, como criterio de utilidad clarificadora".

${ }^{12}$ Artí́culo 1.1.

${ }^{13}$ Artículo 1.2. En relación a los familiares del empresario, quedan excluidos los hijos menores de 30 años, aunque convivan con el empresario, y a los mayores de 30 que tengan especiales dificultades para su inserción laboral. Disposición adicional décima LETA.. y artículo 1.3 e) Estatuto de los Trabajadores (excluye de la aplicación del Estatuto de los Trabajadores a los trabajos familiares, considerados como tales "siempre que convivan con el empresario, el cónyuge, los descendientes, ascendientes y demás parientes por consanguinidad o afinidad, hasta el segundo grado inclusive y, en su caso, por adopción").

${ }^{14}$ Tiene precedentes en otros ordenamientos jurídicos europeos, como es el caso del italiano en el que tiene una configuración jurídica específica la figura del "lavoro parasubordinatto". 
el disponer de infraestructura y materiales propios, el desarrollar su actividad con criterios organizativos propios sin hacerlo de manera indiferenciada con los trabajadores del cliente, el percibir una contraprestación económica y el no ser titular de establecimiento abierto al público ${ }^{15}$. Podemos afirmar, por lo tanto, que a partir de la promulgación de la LETA. ya no existen dos grandes formas de empleo sino tres: autónomo ordinario, asalariado y autónomo económicamente dependiente ${ }^{16}$. Nuestro estudio se centra, precisamente, en la regulación que afecta al primero de ellos, excluyendo a los autónomos económicamente dependientes por contar con una regulación y una problemática más específica.

Dentro del ámbito de la cobertura (o protección) social de los trabajadores autónomos, sin lugar a dudas en la mayor parte de los países europeos la peculiaridad más destacable frente a los niveles alcanzados por los trabajadores asalariados ha sido la ausencia de protección frente a las situaciones de desempleo. En España, así como en la práctica totalidad de los países de nuestro entorno, los trabajadores por cuenta ajena sí tienen derecho a una prestación económica específicamente regulada para dar cobertura a la situación de necesidad que se produce cuando el trabajador se queda sin empleo, cual es la denominada prestación "por desempleo"17. Diversas son las causas que pueden esgrimirse para determinar las razones por las que esta protección no se ha extendido, de alguna forma, también a los trabajadores autónomos ${ }^{18}$. Algunas de ellas se centran en las propias características de estas

${ }^{15}$ Artículo 11 LETA. Tienen un régimen jurídico específico en pues deben formalizar un contrato con el cliente, pueden negociar los denominados "acuerdos de interés profesional” a modo de convenio colectivo, y tienen regulación de jornada y de posibles vicisitudes de dicho contrato. Sobre este régimen jurídico, por todos: ÁlvaREZ DEL Cuvillo, Antonio, El régimen profesional del trabajador autónomo económicamente dependiente, en Cruz Villalón, Jesús - Valdés Dal Re, Fernando (directores), El Estatuto del Trabajo Autónomo (Madrid, La Ley, 2008) pp. 237 ss.; y BARRIos BAUDOR, Guillermo - Sempere NAVARro, Antonio, Régimen profesional del trabajador autónomo económicamente dependiente, en AA.VV. Comentarios al Estatuto del Trabajo Autónomo (Pamplona, Aranzadi, 2010), pp. 207 ss.

${ }^{16}$ En este sentido, Gutiérrez Solar-Calvo, Beatriz - Lahera Forteza, Jesús, Ámbito y fuentes de regulación del trabajo autónomo, CRUZ VILLALÓN, Jesús - VALDÉS DAl Re, Fernando (directores), El Estatuto del Trabajo Autónomo, cit. (n. 15), p. 72.

${ }^{17}$ Regulada, fundamentalmente, en los artículos 203 a 229 Ley General de Seguridad Social (Real decreto legislativo No 1/1994, de 20 de junio) y en el Real decreto No $625 / 1985$, de 25 de abril, que desarrolla la Ley No 31/1984, de 2 de agosto, de protección por desempleo.

${ }^{18}$ Sobre el particular, véase: Cervilla Garzón, María José, La acción protectora de los trabajadores autónomos en el Sistema español de Seguridad Social (Sevilla, Mergablum, 2005), pp. 130-132; y Alarcon Caracuel, Manuel Ramón - Gonzalez Ortega, Santiago, cit. (n. 10), pp. 333 y 334. 
actividades profesionales, sobre todo en lo que respecta a las dificultades que plantea el controlar de forma certera el momento real de su inicio y su cese (no predeterminados por la concertación o extinción de un contrato de trabajo), y a la complicada traslación al ámbito del autoempleo del requisito exigido a los trabajadores asalariados en cuanto a que el desempleo protegido siempre debe ser "involuntario"19. Si los trabajadores asalariados pueden probar la involuntariedad muy fácilmente (extinción de contrato temporal, despido improcedente de su empresario, despido por causas objetivas del trabajador, etcétera), es mucho más difícil la determinación de las situaciones que hayan podido determinar que un trabajador autónomo haya abandonado su actividad empresarial o profesional de forma involuntaria (¿pérdidas en el negocio?:problemas de compatibilidad de la vida familiar y laboral?̨crisis económica en su ámbito de actuación? [...]) y, sobre todo, la acreditación de que dichas circunstancias concurren. Otras en las dificultades para financiar esta cobertura social, puesto que, si supone un incremento de las cotizaciones sociales que deben ingresar los autónomos al Sistema de Seguridad Social, éstas son ya, de por sí, suficientemente elevadas como para incrementarlas aún más, por lo que la inclusión de esta prestación en su acción protectora podría producir el negativo efecto de desincentivar el inicio de proyectos de autoempleo al ser excesivo este coste fijo.

Pero se producen en el ámbito de la Unión Europea y en España, en particular, diversas circunstancias que, en los últimos años, han venido impulsando una modificación de esta situación en aras a incrementar los derechos sociales de estos trabajadores para protegerlos económicamente cuando deben abandonar su actividad profesional. En primer lugar, a nivel europeo una de las líneas prioritarias de las políticas de empleo viene siendo el "fomento del espíritu empresarial"20, acogido por el ordenamiento jurídico español a través de muy diversas normas que abogan por el impulso de una política de fomento del autoempleo ${ }^{21}$, necesaria en el contexto de crisis

${ }^{19}$ Artículo 203.1 Ley general de seguridad social, se encuentra en situación desempleo "quienes, pudiendo y queriendo trabajar, pierden su empleo". PIÑEYROA DE La Fuente, Antonio, Invalidez provisional y trabajadores autónomos, en La Ley, 2 (1992), p. 509.

${ }^{20}$ Forma parte de los cuatro pilares fundamentales de la política de empleo desde el año 1997 (Consejo Europeo Extraordinario sobre Empleo, Luxemburgo), vid. Decisión No 578/2003/CE, del Consejo, de 22 de julio de 2003, relativa a las Directrices para las políticas de empleo de los Estados miembros.

${ }^{21}$ Por una parte, la propia Ley de empleo (Ley No 56/2003, de 16 de diciembre) establece que el fomento del autoempleo es objetivo general de la política de empleo (artículo 2.i) y parte específica de las políticas activas de empleo (artículos $23 \mathrm{ss}$ ). Por otra parte, en el desarrollo que de dicha norma se hace en la Estrategia Española para el Empleo 2012-2014, se contemplan diversas medidas de fomento del autoempleo. Por 
económica en el que actualmente nos encontramos y que nos aboca a muy elevados índices de desempleo. Obviamente, cualquier intencionalidad política de incentivar el número de trabajadores que opten por esta forma de trabajo debe pasar por el establecimiento de un marco jurídico atractivo para la misma, que suprima, en la medida de lo posible, diferencias de trato en los derechos profesionales y sociales reconocidos para los trabajadores.

En segundo lugar, la concertación en España en el año 1995 del conocido como "Pacto de Toledo", documento acordado entre los principales agentes sociales y el gobierno que se tituló "Informe para el análisis de los problemas del Sistema de Seguridad Social y de lasprincipales reformas que deben acometerse", ya puso de manifiesto la intencionalidad política de acometer, en un futuro, una profunda reforma del sistema de protección social de los trabajadores por cuenta propia, con vistas a suprimir desigualdades de trato injustificadas respecto a los derechos de protección social alcanzados por los trabajadores asalariados $^{22}$. Entre ellos, el más significativo era la ausencia de protección frente a las situaciones de desempleo, prestación respecto de la cual, además, existe un imperativo constitucional de integración en nuestro Sistema de Seguridad Social “ex” artículo $41^{23}$.

En tercer lugar, la promulgación de la LETA. en el año 2007 avanza, de forma definitiva, la obligación de crear un sistema de protección social frente a situaciones de cese profesional para los trabajadores autónomos ${ }^{24}$. Así, se incluye en ella una Disposición Adicional Cuarta titulada "Prestación

último, la propia LETA. tiene un título V titulado: Fomento y promoción del trabajo autónomo.

${ }^{22}$ Incluye una recomendación sexta en la que prevé crear sólo dos Regímenes de Seguridad Social, uno para trabajadores autónomos y otro para asalariados. En el año 2001, este Pacto es desarrollado por el "Acuerdo para la Mejora y Desarrollo del Sistema de Protección Social”, firmado entre los sindicatos y organizaciones empresariales más representativas y el gobierno, en el que se plantea, directamente, la mejora de la acción protectora de los autónomos del RETA., homogeneizando su protección social con los trabajadores asalariados. Vèase: Cervilla Garzón, María José, cit. (n. 18), pp. 59 ss.; y Monereo Perez, Jose Luis, La nueva fase del desarrollo del Pacto de Toledo: el acuerdo para la mejora y el desarrollo del Sistema de protección social, en Relaciones Laborales, 24 (diciembre de 2001).

${ }^{23}$ Según el cual: "Los poderes públicos mantendrán un régimen público de Seguridad Social para todos los ciudadanos que garantice la asistencia y prestaciones sociales suficientes ante situaciones de necesidad, especialmente en caso de desempleo".

${ }^{24}$ Previamente, la Ley No 53/2002, de 30 de diciembre, de Medidas urgentes administrativas, fiscales y de orden social, incluyó una disposición final sexta en la que ya se avanzaba la intencionalidad política de regular estas prestaciones. En ella se establecía la necesidad de que se emitiese un informe durante el primer semestre del año 2003, para establecer un posible fondo de garantía en caso de cese por causas objetivas de los trabajadores autónomos económicamente dependientes. 
por cese de actividad" con el siguiente tenor: "El Gobierno, siempre que estén garantizados los principios de contributividad, solidaridad y sostenibilidad financiera y ello responda a las necesidades y preferencias de los trabajadores autónomos, propondrá a las Cortes Generales la regulación de un sistema especifico de protección por cese de actividad para los mismos, en función de sus caracteristicas personales o de la naturaleza de la actividad ejercida". El título de la misma fue muy significativo, puesto que ya avanzó que la intención del gobierno no era hacer extensible, sin más, la prestación por desempleo de los asalariados a los trabajadores autónomos, sino que se pretendía regular una prestación totalmente novedosa y adaptada a las peculiaridades de este colectivo $^{25}$. También se puede deducir del contenido de la disposición que la futura prestación no va a tener una naturaleza asistencial, sino que va a estar ligada a las prestaciones de corte contributivo, es decir, financiada con las cotizaciones de los trabajadores por cuenta propia ${ }^{26}$.

En cumplimiento de esta previsión, se presentó un Informe por una Comisión de Expertos, designada por el Ministerio de Trabajo e Inmigración, para el estudio del establecimiento de un sistema específico de protección por cese de actividad a favor de los trabajadores autónomos ${ }^{27}$. Posteriormente, la tan esperada cobertura frente a situaciones de cese profesional obligatorio para los trabajadores autónomos se produce con la promulgación de la Ley No 32/2010, de 5 de agosto, por la que se establece un sistema específico de protección por cese de actividad de los trabajadores autónomos ${ }^{28}$. Al análisis de los aspectos fundamentales de su contenido (los relativos a objeto de la protección, sujetos amparados, contenido, duración y cuantía) en lo que

${ }^{25}$ Sobre el particular, Cervilla Garzón, María José, La reforma "pro futuro" de la protección social de los trabajadores autónomos tras la aprobación de su nuevo Estatuto, en Actualidad Laboral, 19 (2008), p. 2292; y López Gandía, Juan - TosCani GiméNEZ, Daniel, El régimen profesional y de Seguridad Social de los Trabajadores Autónomos (Madrid, El Derecho, 2010), p. 152.

${ }^{26}$ Monereo Pérez, Jose Luis - Fernández Avilés, Jose Antonio, Los derechos de protección social de los trabajadores autónomos (Granada, Comares,, 2009), p. 92.

${ }^{27}$ Presentado en diciembre de 2008, cuyos miembros fueron Santiago Carbo Valverde, Francisco Rodríguez Fernandez, Salvador del Rey Guanter, Valeriano Gomez Sanchez, Teresa Quílez Félez, Eduardo Ruiz Muñoz de Baena y Fernando Valdés ValRe (coordinador de la Comisión). Está publicado por el Ministerio de Trabajo e Inmigración bajo el título Propuesta de viabilidad de un sistema de prestación por cese de actividad de los trabajadores autónomos (Madrid, 2009). Para un análisis de su contenido: Cervilla Garzón, María José, El esperado informe sobre la prestación por cese de actividad: análisis del ámbito subjetivo, hecho causante, dinámica, cuantía y diseño financiero, en Documentación Laboral, 87 (2009); y Jover Ramirez, Carmen, El informe sobre la protección por cese de actividad: promoción del trabajo autónomo, prestación y jubilación, gestión y régimen sancionador en Documentación Laboral, 87 (2009).

${ }^{28}$ Boletin Oficial del Estado de 6 de agosto de 2010. 
afectan a los autónomos no considerados económicamente dependientes, vamos a dedicar las páginas que siguen.

Pero hay una cuestión que, "a priori”, puede parecer bastante significativa. Se trata del rango de la norma que ha procedido a dar carta de naturaleza a esta nueva contingencia. Si atendemos a la regulación de otras prestaciones singularmente importantes en el Sistema español de Seguridad Social como son la incapacidad temporal, la maternidad o el riesgo durante el embarazo, el legislador no ha recurrido a normas de rango legal, sino que su desarrollo se ha producido vía Real-decreto ${ }^{29}$. No se explicaría esta diferencia de trato si no tuviéramos en cuenta que todas ellas están contempladas, expresamente, en la Ley general de seguridad social, y en ella se encuentran sus postulados más básicos. Los posteriores Reales decretos sólo se centran en desarrollar los principios que esta norma general ya había apuntado. La prestación que comentamos, sin embargo, no está mencionada como tal en la Ley general de seguridad social, sólo en la LETA. en su Disposición Adicional Cuarta. En caso de que esta norma hubiese actuado como aquella (es decir, ofreciendo un marco genérico de referencia al legislador), con toda seguridad la normativa de desarrollo habría sido, así mismo, un Real decreto. Hubiese sido deseable tal actividad legislativa pero, probablemente, por la complejidad que plantea la configuración jurídica de una situación hasta el momento absolutamente desprotegida, de la cual se carecen de referentes en otros ordenamientos jurídicos, el papel de la LETA. en relación a esta prestación quedó en una mera recomendación al Gobierno sobre la necesidad de articular la protección ${ }^{30}$. Y no de forma inmediata, sino cuando "están garantizados los principios de contributividad, solidaridad y sostenibilidad financiera" o, lo que es lo mismo, cuando el Gobierno dispusiera de recursos financieros suficientes para afrontar el pago de la misma ${ }^{31}$. Ante esta ausencia de referentes, nos parece que, sin duda, la nueva prestación debía quedar regulada por una norma con rango de Ley, como así ha sido. Y ello aun cuando la LETA no hacía ninguna indicación en este sentido.

${ }^{29}$ Real decreto No $^{0} 1.251 / 2001$, de 16 de noviembre, para la maternidad y el riesgo durante el embarazo y el Real decreto No 575/1997, de 18 de abril, para el control de la incapacidad temporal.

${ }^{30}$ En este sentido: Monereo Pérez, José Luis - Fernández Avilés, José Antonio, cit. (n.26), p. 91.

${ }^{31}$ Sobre esta cuestión ya hicimos un comentario en El esperado informe sobre la prestación por cese de actividad: análisis del ámbito subjetivo, becho causante, dinámica, cuantía y diseño financiero, cit. (n. 27), pp. 85 ss. y bibliografía allí citada. 


\section{OBJETO DE LA PROTECCIÓN}

Debemos, en primer lugar, hacer referencia a cual es la situación de necesidad protegida en la Ley, pues no todo cese en la actividad de los trabajadores por cuenta propia va a dar derecho a solicitar el abono de esta prestación. Los parámetros de referencia básicos van a ser los siguientes ${ }^{32}: i$ ) Cese total de la actividad, que puede ser definitivo o temporal; y ii) Afectación a los trabajadores autónomos que pueden y quieren ejercer una actividad por cuenta propia, pero han tenido que cesar en ella.

La necesidad de que el cese sea total viene determinada por el hecho de que el ordenamiento jurídico español no cuenta, en la actualidad, con una regulación del posible desarrollo de actividades autónomas de forma parcial, aun cuando sí está ya prevista la figura del autónomo a tiempo parcial ${ }^{33}$. Los numerosos problemas jurídicos que plantea la configuración de este trabajo parcial entendemos que van a seguir dificultando tal desarrollo reglamentario $^{34}$ (pues ¿̇como se efectúa el control, si el autónomo ordinario se caracteriza por no estar sometido a ninguna regulación en materia de jornada?).

Otra problemática específica que plantea el necesario cese total viene dado por la situación en la que el trabajador por cuenta propia realice más de una actividad económica o profesional de forma autónoma. En estos casos, el Sistema español de Seguridad Social exige que el alta que debe solicitarse ante la Tesorería General de la Seguridad Social es única ${ }^{35}$, por lo que no tiene el Sistema constancia de cuántas actividades se desarrollan simultáneamente de forma autónoma. En cualquier caso, aun cuando el precepto nada dice,

\section{${ }^{32}$ Artículo 1.}

${ }^{33}$ la Ley No 27/2011, de 1 de agosto, sobre actualización, adecuación y modernización del Sistema de Seguridad Social, en su Disposición final décima modifica el artículo 1, apartado 1 LETA, estableciendo que la actividad autónoma podrá hacerse a tiempo completo o a tiempo parcial. Esta norma, sin embargo, todavía carece de desarrollo reglamentario.

${ }^{34}$ Sánchez-Uran Azaña, Yolanda, El desempleo de los trabajadores autónomos. Un estudio de la Ley 32/2010, de 5 de agosto, por la que se establece un sistema especifico de protección por cese de actividad de los trabajadores autónomos (Madrid, Thomsom Reuters, 2010), p. 105.

${ }^{35}$ Artículo 41 Real Decreto No 84/1996, de 26 de enero, por el que se aprueba el Reglamento general sobre inscripción de empresas, afiliación, altas, bajas y variaciones de datos de trabajadores en la seguridad social. En el Sistema español de Seguridad Social las altas son los actos administrativos en virtud de los cuales se comunica, a través de la entidad gestora competente, que es la Tesorería General de la Seguridad Social, la realización de actividades profesionales incluidas en el Sistema y por las cuales hay obligación de cotizar. Sobre el particular, por todos: Rodríguez Ramos, María José - Vilchez Porras, Maximiliano - Gorelli Hernández, Juan, Sistema de Seguridad Social (3a edición, Madrid, Tecnos, 2001), pp. 192 ss. 
si aplicamos la regla de incompatibilidad establecida entre el percibo de la prestación y el desarrollo de actividades por cuenta propia ${ }^{36}$, en ningún caso va a ser admisible la solicitud de la prestación por el cese en una actividad ejercida por cuenta propia sí se mantienen otras diferentes.

Sobre las causas que pueden provocar el cese, en un epígrafe posterior analizaremos las posibles situaciones legales de cese que se contemplan. Pero, en cualquier caso, debe tenerse en cuenta que este cese no debe quedar protegido por otras prestaciones de Seguridad Social cuya cobertura se reconoce a los trabajadores por cuenta propia. Nos referimos a los ceses obligados por padecer un accidente o una enfermedad, de orígen común o profesional, por el retiro definitivo de la vida profesional o por estar en situaciones de maternidad, paternidad, riesgo durante la lactancia o durante el embarazo ${ }^{37}$.

Por otra parte, la exigencia en cuanto a que deben "querer" ejercer su actividad pone de manifiesto que la situación protegida no es, en ningún caso, una situación de cese voluntario o querido por el trabajador, sino que éste debe producirse de forma no evitable. Este requisito se transcribe casi como una copia del exigido a los asalariados para cobrar el desempleo en la Ley general de seguridad social ${ }^{38}$, aun cuando, en este ámbito, ya comentamos que tiene mucha más dificultad su control. Al determinar las situaciones legales de cese permitidas veremos las exigencias que se imponen.

\section{SUJETOS PROTEGIDOS Y REQUISITOS QUE DEBEN CUMPLIR}

Anteriormente comentamos que el trabajo autónomo es una forma de empleo que se puede ejercer de formas muy variadas, cada una de ellas sometidas a un régimen jurídico diferente. Tenemos, pues, que delimitar, cuales van a ser las formas de trabajo autónomo que van a quedar protegidas ante estas situaciones. La norma hace referencia a dos cuestiones diferentes: por una parte, los concretos colectivos de autónomos protegidos; por otra, los requisitos que a éstos autónomos se les va a exigir para poder acceder a la prestación (los denominados requisitos del "hecho causante").

\section{Colectivos con cobertura prestacional.}

En términos generales, todos los trabajadores incluidos en nuestro

\footnotetext{
${ }^{36}$ Artículo 12: "La percepción de la prestación económica [...] es incompatible con el trabajo por cuenta propia”.

${ }^{37}$ Se trata de las prestaciones por incapacidad temporal, incapacidad permanente, jubilación, maternidad, paternidad, riesgo durante la lactancia materna y riesgo durante el embarazo. Artículo 26.1 b) LETA.

${ }^{38}$ Artículo 203.1.
} 
Sistema de Seguridad Social como autónomos van a quedar protegidos ${ }^{39}$. Actualmente los autónomos pueden estar integrados, bien en el RETA., o bien en el Régimen Especial de los Trabajadores del Mar. Este último es de carácter muy residual, y sólo incluye a autónomos que trabajan en este sector pero con unas peculiaridades muy específicas que se dan en pocos $\operatorname{casos}^{40}$. Por ello, el Régimen de referencia para los autónomos es el RETA., siendo necesario que los trabajadores tengan cubierta la protección dispensada por contingencias profesionales ${ }^{41}$ para estar el ámbito de cobertura de esta prestación. Debemos, pues, hacer referencia, a los requisitos exigidos por nuestro Sistema de Seguridad Social a los autónomos, en el desarrollo de su actividad, para quedar obligatoriamente incluidos en alguno de estos Regímenes (idénticos en los dos anteriormente mencionados). Básicamente los condicionantes que deben regir su actividad son los siguientes: $i$ ) que sea habitual; ii) que tenga ánimo de lucro; $i i i$ ) que se realice de forma personal y directa; $i v$ ) independientemente de si tienen trabajadores o no a su cargo; y $v$ ) en caso de tener un establecimiento abierto al público, se presume la consideración de trabajo autónomo iuris tantum.

De forma específica se hace mención a la inclusión en el ámbito subjetivo de la prestación a los autónomos del sector agrario, los que son socios trabajadores de cooperativas y los que ejercen su actividad conjuntamente. Respecto a estos dos últimos, existen normas particulares para acreditar la situación de cese involuntario, que a continuación mencionamos.

\section{Requisitos del hecho causante,}

Los requisitos básicos que deben cumplir los autónomos solicitantes de la prestación van a ser los siguientes ${ }^{42}$ :

i) Estar afiliados y en alta en el Sistema de Seguridad Social, así como tener cubiertas las contingencias profesionales ${ }^{43}$.

ii) Tener cubierto el período mínimo de cotización previsto, que se sitúa

${ }^{39}$ Artículo 2.

${ }^{40}$ Este régimen se regula, fundamentalmente, en el Decreto No 2.864/1974, de 30 de agosto, que aprueba el Texto Refundido de su Ley. Según su artículo 2, sólo quedan en él incluidos los autónomos que sean armadores de embarcaciones pequeñas, se dediquen a la extracción de productos del mar o sean rederos por cuenta propia. Esta actividad debe ser, además, su medio fundamental de vida, por lo que deben obtener de ella sus principales ingresos profesionales. Sobre el particular: CANOsa RoDRIGo, Manuel, Campo de aplicación del Régimen Especial de la Seguridad Social de los Trabajadores del Mar, en Tribuna Social, 49 (1995).

${ }^{41} \mathrm{Su}$ cobertura no es obligatoria para los autónomos, pueden no cotizar por esta contingencia.

${ }^{42}$ Artículo 4

${ }^{43}$ La cobertura de estas contingencias en el RETA.. tiene carácter voluntario "ex" 
en doce meses dentro de los cuarenta y ocho inmediatamente anteriores a la situación legal de cese ${ }^{44}$.

iii) Encontrarse en situación legal de cese de actividad, suscribir el compromiso de actividad y acreditar activa disponibilidad para la reincorporación al mercado de trabajo a través de las actividades formativas y de orientación a las que pueda convocarle el Servicio Público de Empleo. La mención a la suscripción del compromiso de actividad supone aplicar a los trabajadores autónomos la misma obligación que se impone a los trabajadores asalariados en la Ley general de seguridad social ${ }^{45}$. En este sentido, dicho compromiso conlleva la aceptación de una "colocación adecuada" en los términos establecidos en dicha norma ${ }^{46}$.

iv) No haber cumplido la edad ordinaria para acceder a la pensión de jubilación, salvo que el trabajador autónomo no tuviera acreditado el periodo mínimo de cotización requerido para ello.

v) Hallarse al corriente en el pago de las cuotas a la Seguridad Social. Pero es también de aplicación para esta prestación el mecanismo de flexibilización de este requisito previsto para todas las prestaciones reconocidas a los trabajadores por cuenta propia. Así, la Entidad Gestora de la prestación solicitada debe invitar al ingreso de las cuotas pendientes $y$, si dicho ingreso se produce en un plazo de treinta días, se entiende cumplido el requisito ${ }^{47}$.

vi) Si el autónomo es empleador (es decir, tiene algún trabajador a su cargo), es requisito previo al cese el cumplimiento de las garantías, obligaciones y procedimientos regulados en la legislación laboral. Quiere decirse con ello

disposición adicional trigésimo cuarta Ley general de seguridad social, con el correspondiente incremento en sus cotizaciones en caso de aceptar la cobertura.

${ }^{44}$ Artículo 8.

${ }^{45}$ Artículo 231.

${ }^{46}$ La delimitación jurídica de lo que debe entenderse por "colocación adecuada" se ha realizado de forma extraordinariamente extensa y compleja en el precepto antes citado. En términos generales, se considera como tal aquella que corresponda con su profesión habitual, cualquier otra que se ajuste a sus aptitudes físicas o formativas y, en cualquier caso, la coincidente con la última actividad laboral desempeñada si ha durado más de tres meses. Cuando haya transcurrido un año como beneficiario de la prestación, podrá ser adecuada otra colocación que, a juicio del Servicio Público de Empleo, pueda ser ejercida por el trabajador.

${ }^{47}$ Disposición adicional trigésimo novena de la Ley general de seguridad social y artículo 28.2 del Decreto No 2.530/1970, de 20 de agosto. Además, si el ingreso se realizase fuera de dicho plazo, se concederá la prestación menos un 20 por 100, si se trata de prestaciones de pago único y subsidios temporales; si se trata de pensiones, se concederán las mismas con efectos a partir del día primero del mes siguiente a aquel en que tuvo lugar el ingreso de las cuotas adeudadas. Sobre el particular: Desdentado Bonete, Aurelio - Tejerina Alonso, José Ignacio, La acción protectora del régimen especial de los trabajadores por cuenta propia o autónomos (Valladolid, Lex Nova, 2004), p. 213. 
que, tal y como obliga el ordenamiento jurídico-laboral español, la extinción de los contratos de sus trabajadores debe seguir los cauces legalmente previstos, básicamente a través del procedimiento de despido colectivo conocido como los Expedientes de Regulación de Empleo ${ }^{48}$.

\section{Configuración jurídica de la situación legal de cese}

Probablemente, el aspecto más espinoso de esta regulación se encuentra en la delimitación de los supuestos que determinan las situaciones legales en que debe encontrarse un autónomo para poder solicitar la prestación. Como anteriormente poníamos de manifiesto, el cese en la actividad debe tener un carácter involuntario, es decir, no directamente querido o provocado por el trabajador por cuenta propia, con la dificultad probatoria que esta exigencia puede tener. Así se reitera en esta norma al declarar que, en ningún caso, estarán en situación legal de cese "aquellos que cesen o interrumpan voluntariamente su actividad"'49.

a) General. En general, se va a encontrar en situación legal de cese el autónomo que cesa en el ejercicio de su actividad por alguna de las siguientes causas $^{50}$ :

i) Concurrencia de motivos económicos, técnicos, organizativos o de producción, determinantes de la inviabilidad de proseguir la actividad económica o profesional. Fundamentalmente, esta exigencia va a determinar que el autónomo debe tener pérdidas económicas reales y actuales para poder acreditar una situación de cese legal, sin que pueda admitirse la acreditación de pérdidas potenciales o futuras ${ }^{51}$. Se entenderá que existen si se producen alguna de las situaciones siguientes. Por una parte, pérdidas en el ejercicio superiores al 30\% de los ingresos en un año, o superiores al 20\% en dos años consecutivos. Se plantea aquí un problema no resuelto por la norma, en cuanto a que los trabajadores autónomos pueden desarrollar diversas actividades profesionales, dándose ésta pérdida en alguna de ellas pero en otras no. En estos casos, habrá que determinar si el autónomo podría cesar en todas y solicitar la prestación, o debería acreditar estas pérdidas en cada una de ellas $^{52}$. Por otra parte, ejecuciones judiciales tendentes al cobro de deudas que comporten, al menos, el 40\% de los ingresos en el año anterior. Por último, declaración judicial de concurso que impida continuar su actividad ${ }^{53}$. Para

\footnotetext{
${ }^{48}$ Artículo 51 del Estatuto de los trabajadores.

${ }^{49}$ Artículo 5.3 a).

${ }^{50}$ Artículos 5 y 6 .

${ }^{51}$ Sánchez-Uran Azaña, Yolanda, cit. (n. 34), p. 132.

${ }^{52}$ En opinión de Sánchez-Uran Azaña, Yolanda, cit. (n. 34), p. 128, sólo se computan las pérdidas en la actividad que se alegue para cobrar la prestación.

${ }^{53}$ Según lo previsto en la Ley No 22/2003, de 9 de julio, Concursal, procedimiento
} 
probar estas circunstancias, el trabajador deberá aportar declaración jurada y documentos contables, profesionales, fiscales, administrativos o judiciales que lo acrediten. Si el autónomo tiene establecimiento abierto al público, se exige su cierre.

ii) Concurrencia de fuerza mayor, en referencia a fenómenos naturales o sucesos de carácter totalmente imprevisible e inevitable. Esto debe acreditarse mediante declaración jurada y declaración del órgano gestor en que se ubique el negocio o la industria afectada.

iii) Pérdida de la licencia administrativa, si es requisito para el ejercicio de la actividad y no está motivada por incumplimientos contractuales, la comisión de infracciones administrativas o delitos imputables al autónomo. Debe acreditarse aportando la resolución administrativa en la cual consta.

iv) Violencia de género de la trabajadora autónoma, acreditada con la orden de protección o el informe del Ministerio Fiscal que lo indique.

v) Divorcio o acuerdo de separación matrimonial, si el autónomo ejercía funciones de ayuda familiar en el negocio de su excónyuge y éstas dejan de ejercerse a causa de la ruptura. Ello debe acreditarse mediante la correspondiente resolución judicial de divorcio o separación.

b) Socios trabajadores de cooperativas. En el ordenamiento jurídico español, la cooperativa, como forma jurídica de empresa, se define como "una sociedad constituida por personas que se asocian, en régimen de libre adhesión y baja voluntaria, para la realización de actividades empresariales, encaminadas a satisfacer sus necesidades y aspiraciones económicas y sociales, con estructura y funcionamiento democrático ${ }^{54}$. La actividad de los socios trabajadores en ellas presenta diversas particularidades y, por ello, la acreditación de las situaciones legales de cese tiene un tratamiento específico en la ley comentada. Se les permite la afiliación al Sistema de Seguridad Social como trabajadores autónomos ${ }^{55}$, pero en su régimen jurídico coexisten caracteres propios de las actividades autónomas (incluso la ley califica la relación

previsto para empresas en situación de insolvencia acreditada como instrumento para abonar el pago a los acreedores.

${ }^{54}$ Su régimen jurídico está básicamente establecido en la Ley No 27/1999, de 16 de julio, de cooperativas.

${ }^{55}$ Disposición adicional cuarta de la Ley general de seguridad social, les permite optar en sus Estatutos entre ser autónomos o asalariados. 
profesional como de "societaria") ${ }^{56}$ y de las asalariadas ${ }^{57}$, de ahí la dificultad

${ }^{56}$ En primer lugar, los socios son retribuidos a través de los denominados "anticipos societarios", los cuales, según la propia ley, no tienen la consideración de salarios (artículo 80.4); en segundo lugar, y este dato es mucho más determinante, la cooperativa se constituye con participaciones de los socios (artículo 13.3) la cual está, por una parte, afecta al pago de las deudas sociales (artículo 15.3), por otra, condiciona la retribución anual por su participación al resultado positivo en el ejercicio económico (artículo 48.2); por último, los órganos rectores de la cooperativa se constituyen con los propios socios (artículos 19 y ss.), y son ellos los que van a determinar las decisiones relativas a la realización de la actividad objeto de la cooperativa, lo que nos parece un rasgo de independencia más fuerte que el quedar sometidos a jornadas $u$ horarios de trabajo. No existe, sin embargo, unanimidad doctrinal ni jurisprudencial en este sentido. De hecho, sobre las prestaciones de servicios llevadas a cabo por estos trabajadores existen fundamentalmente tres posturas doctrinales y jurisprudenciales: aquella que la califica como laboral. Un exponente de esta corriente es Álvarez Alcolea, Manuel, La condición jurídico-laboral de los socios de las cooperativas de producción en Revista de Politica Social, 10 (1975). Aquella otra que la califica de societaria (la que ha venido siguiendo mayoritariamente la jurisprudencia anterior a la publicación de la ley actual, entre otras, sentencias del Tribunal Supremo, de 12 de junio de 1987, Ar: 434 y de 6 de Mayo de 1988, Ar: 3571); y una tercera que la califica de naturaleza mixta. Esta última, uno de cuyos primeros precursores fue Montoya Melgar, Alfredo, Sobre el socio-trabajador de la cooperativa de trabajo asociado, en AA. VV., Estudios de Derecho del Trabajo en memoria del Profesor Gaspar Bayón Chacón (Madrid, Tecnos, 1980) p. 145 , cuenta con bastante aceptación en la actualidad, a nivel doctrinal, como es el caso de Alonso Soto, Las relaciones laborales en las cooperativas en España, en Revista de Derecho del Trabajo, 20 (octubre-diciembre 1984), pp. 543; Dueñas Herrero, El ámbito subjetivo de las cooperativas de trabajo asociado, en AA.VV., I Congreso de Castilla y León sobre Relaciones Laborales (Valladolid, Lex Nova, 1999), pp. 283 ss.; y Luján Alcaráz, Juan, El socio trabajador de las cooperativas de trabajo asociado en la L. 27/1999, de 16 de julio, de Cooperativas, en Aranzadi Social, 5 (1999), pp. 129 ss. A nivel jurisprudencial, entre otras se pronuncian las sentencias de los Tribunales Superiores de Justicia de Cataluña de 8 de febrero de 1999 (Ar: 887), Fto. Jco. primero, en la que se dice que hay dos relaciones jurídicas y sólo una es de carácter laboral; Castilla y León de 20 de septiembre de 1999 (Ar: 613); Murcia de 2 de noviembre de 1999 (Ar: 3792), en cuyo Fto. Jco. tercero califica a la relación de un tertium genus. Sobre esta cuestión, sin embargo, existe numerosísima doctrina, aparte de los autores ya citados podemos destacar también las obras sobre el particular de Santiago Redondo, Koldo, Socio de cooperativa y relación laboral (Madrid, ibídem, 1999); y VALDÉS DAL $\mathrm{RE}$, Fernando Las relaciones de trabajo en las cooperativas de trabajo asociado en AA. VV., Primeros encuentros cooperativos de la Universidad del País Vasco (Vitoria-Gastéiz, ediciones Gobierno Vasco, 1986).

${ }^{57} \mathrm{La}$ doctrina distingue en su legislación aplicable entre tres tipos de normas: societarias, mixtas (normas integradas en la legislación cooperativa pero con instituciones típicamente laborales) y laborales; por todos: GonZÁLEZ DE PATTO, Rosario El nuevo régimen jurídico de las relaciones de trabajo en las cooperativas de trabajo asociado: ambivalencias en el proceso de laboralización del socio trabajador, en Temas Laborales, 53 
doctrinal para encuadrar esta forma de trabajo en una u otra categoría.

Las situaciones legales de cese, previstas para éstos trabajadores ${ }^{58}$, van a ser las siguientes:

i) Expulsión improcedente de la cooperativa (es igual al despido improcedente de los trabajadores asalariados, es decir, el despido efectuado sin causa justa). Debe acreditarse con la resolución que acredita la improcedencia del despido.

ii) Causas económicas, técnicas, organizativas, productivas o de fuerza mayor. Se acreditan con los mismos documentos que otros autónomos, incluyendo certificación del acuerdo de la asamblea general de la cooperativa del cese de la actividad de los socios.

iii) Finalización del periodo, en caso de vínculo societario de duración determinada.

iv) Violencia de género de las socias trabajadoras, que debe acreditarse en los mismos términos que otros autónomos.

v) Pérdida de la licencia administrativa de la cooperativa.

vi) Cese durante el periodo de prueba de los aspirantes a socio, acreditada con el acuerdo de no admisión por parte del órgano de administración de la cooperativa.

En cualquier caso, si el socio percibe la prestación por cese de actividad al acreditar alguna de estas circunstancias pero vuelve a ingresar en la misma cooperativa en el plazo de un año, deberá reintegrar la prestación percibida. El legislador, en estos casos, presume la existencia de fraude y obliga a los socios a que el cese sea definitivo.

c) Autonomos que ejercen su actividad conjuntamente. También se establecen particularidades en la determinación de las situaciones legales de cese de aquellos autónomos que venían ejerciendo su actividad profesional conjuntamente con otros en régimen societario (sociedades mercantiles o civiles, salvo las cooperativas anteriormente citadas) u otra forma jurídica admitida en derecho (como podrían ser las comunidades de bienes $)^{59}$. Bien es cierto que todas las situaciones legales de cese son idénticas a las establecidas en los dos supuestos anteriores (motivos económicos, fuerza

(2000), p. 67. Como normas de contenido típicamente laboral aplicables a la relación de trabajo de los socios trabajadores, destacamos, como más llamativas, las relativas a su sometimiento a un régimen disciplinario establecido en sus Estatutos (artículo 82), la regulación de su jornada de trabajo, descanso semanal, fiestas, vacaciones y permisos (artículo 83), determinación de los supuestos de suspensión y excedencias en la relación de trabajo (artículo 84) y sometimiento de las cuestiones contenciosas que se susciten entre el socio y la cooperativa al Orden Jurisdiccional Social (artículo 87).

${ }^{58}$ Disposición adicional sexta.

${ }^{59}$ Disposición adicional séptima. 
mayor, pérdida de licencia administrativa, violencia de género o divorcio o acuerdo de separación matrimonial), no se establece ninguna novedad. Lo que sí se incluyen son dos matizaciones en cuanto a la alegación de los motivos económicos por parte de los socios. Por una parte, que, en estos casos, no se obliga al cierre del establecimiento abierto al público si no cesan todos los socios de la entidad. Por otra, de forma idéntica a lo previsto para las cooperativas, si el socio percibe la prestación por cese de actividad y vuelve a ejercer la actividad profesional en la misma entidad en el plazo de un año, deberá reintegrar la prestación percibida.

\section{CONTENIDO DE LA ACCIÓN PROTECTORA}

Si atendemos al contenido que nuestro ordenamiento jurídico otorga a la prestación por desempleo reconocida a los trabajadores asalariados, podremos observar que se compone de distintos beneficios que pueden ser transportados a los trabajadores por cuenta propia. Y ello porque, en este ámbito de la prestación, los trabajadores ya no tienen diferencias por su forma de ejercer la actividad, todos están en un mismo plano de igualdad en cuanto el desarrollo de la misma ya se ha extinguido. La Ley general de seguridad social reconoce a los asalariados el derecho a una prestación económica (la denominada "prestación por desempleo"), el beneficio de que la Tesorería General de la Seguridad Social abone parte de las cotizaciones del desempleado mientras cobra la prestación (pues durante su cobro se mantiene la obligación de cotizar) y el derecho a acciones de formación, perfeccionamiento, orientación e inserción profesional ${ }^{60}$.

Evitando desigualdades al respecto, para los trabajadores autónomos el contenido de la protección se basa en esos mismos pilares ${ }^{61}$. En primer lugar, se reconoce el derecho al cobro de una prestación económica, que tendrá carácter temporal al igual que la prestación por desempleo. En segundo lugar, el autónomo también mantiene la obligación de cotizar al Sistema durante el cobro de la prestación, pero el abono de su cotización por contingencias comunes lo asumirá la entidad gestora. Como única excepción, no existe la obligación de cotizar cuando el cese es debido a violencia de género, pues ello lo impone la Ley orgánica No 1/2004, de 28 de diciembre, sobre:Medidas de protección integral para la violencia de géner $0^{62}$. En este caso, la regulación es

${ }^{60}$ Artículo 206. Sobre el particular, por todos: Poquet Catala, Raquel Protección por desempleo: el sistema tras las últimas reformas (Valencia, Tirant Lo Blanch, 2008).

${ }^{61}$ Artículo 3.

${ }^{62}$ En la Ley se contempla un plazo de exención de seis meses, como indican LópEZ Gandía, Juan - Toscani Giménez, Daniel, cit. (n. 25), p. 155, si la duración de la prestación es mayor sí se reanudará la obligación de cotizar. 
diferente a la establecida para los asalariados porque su sistema de cotización también es distinto. En el caso de los asalariados, el hecho de que su cuota tenga una parte que debe pagar su empresario (la que se conoce como "cuota patronal") y otra que debe abonar el trabajador (la denominada "cuota obrera") permite que, en caso de situación por desempleo, la cuota patronal es la que asumirá la entidad gestora. La cotización de los autónomos carece de esta característica, puesto que no existe empresario al que derivar parte del pago, y por ello asumen su abono en total. Es imposible, pues, que el descuento de la cotización en situación de cese se produzca de esa manera, habiendo optado el legislador por una fórmula muy beneficiosa para el autónomo cual es descontarle todo lo correspondiente a la cotización por contingencias comunes, que es la parte de obligatoria asunción para todos. En cuanto a la entidad gestora que deberá proceder al abono, en el caso de los trabajadores autónomos dicha entidad puede ser la establecida por el Sistema de Seguridad Social o una Mutua de Accidente de Trabajo y Enfermedad Profesional, si el trabajador optó por una de ellas.

Por último, también este colectivo tendrá derecho a estar incluido en medidas de formación, orientación profesional y promoción de la actividad emprendedora, que se financiarán con el $1 \%$ de los ingresos obtenidos en cotizaciones y que llevarán a cabo el Servicio Público de Empleo Estatal o el Instituto Social de la Marina (para los autónomos de sector marítimopesquero). Nótese como hay una intencionalidad de que el trabajador que ya fue autónomo siga manteniendo el espíritu emprendedor, puesto que esa referencia a la inclusión en medidas de promoción de la actividad emprendedora no está prevista para los trabajadores asalariados desempleados.

\section{DURACIÓN Y CUANTÍA DE LA PRESTACIÓN ECONÓMICA}

Estos aspectos, fundamentales en el régimen jurídico de esta prestación, no tienen ningún paralelismo con la prestación por desempleo contributiva de los trabajadores asalariados. En ambos casos existen amplias diferencias en las que se pone de manifiesto la infraprotección otorgada a los trabajadores autónomos, probablemente causada por la falta de tradición en la cobertura de sus situaciones de cese de actividad y por los problemas de financiación que ya comenzaba a padecer el Sistema de Seguridad Social español en la fecha de su regulación.

En lo que a la duración de la prestación económica se refiere ${ }^{63}$, al igual que en la prestación por desempleo ésta vendrá determinada por el número de meses cotizados al Sistema de Seguridad Social, incrementándose la du-

${ }^{63}$ Artículo 8. 
ración en proporción directa al incremento de mensualidades cotizadas. Así, partiendo de que el autónomo debe tener cotizados doce meses continuados dentro de los cuarenta y ocho anteriores a la situación legal de desempleo, la proporción establecida es la siguiente:

i) Entre doce y diecisiete meses cotizados le corresponden dos meses de prestación.

ii) Entre dieciocho y veintitrés meses cotizados le corresponden tres meses de prestación.

iii) Entre veinticuatro y veintinueve meses cotizados le corresponden cuatro meses de prestación.

$i v$ ) Entre treinta y treinta y cinco meses cotizados le corresponden cinco meses de prestación.

v) Entre treinta y seis y cuarenta y dos meses cotizados le corresponden seis meses de prestación.

vi) Entre cuarenta y tres y cuarenta y siete meses cotizados le corresponden ocho meses de prestación.

vii) De cuarenta y ocho en adelante meses cotizados le corresponden doce meses de prestación.

La duración se incrementa si los autónomos la solicitan una vez cumplidos los sesenta años ${ }^{64}$.

En relación a la prestación por desempleo, que puede alcanzar un máximo de 720 días si se acreditan aproximadamente seis años $\operatorname{cotizados}^{65}$, es evidente que el autónomo queda en peor situación. También es peor la situación en que queda el autónomo que ha agotado su duración máxima, pues tendrá que esperar a que transcurran dieciocho meses desde el reconocimiento del último derecho a la prestación.

Por último, están establecidas una serie de reglas, similares a las establecidas para los trabajadores asalariados, en cuanto a las cotizaciones que van a ser tenidas en cuenta para calcular la duración de la prestación. Así, sólo computarán las realizadas al RETA., o al Régimen Especial de Trabajadores del Mar (y no, por ejemplo, las que hayan podido ser ingresadas en otro Régimen como trabajador asalariado, lo cual fácilmente puede ocurrir si el autónomo es, a la vez, trabajador por cuenta ajena, estando en situación de pluriempleo) y las que no hubiesen sido computadas para generar un derecho anterior.

En lo referente a su cuantía ${ }^{66}$, el porcentaje aplicable a la base reguladora es el mismo previsto para la prestación por desempleo durante sus primeros

\footnotetext{
${ }^{64}$ Disposición adicional primera:

${ }^{65}$ Ley general de seguridad social, artículo 210.

${ }^{66}$ Artículo 9.
} 
ciento ochenta días, el $70 \%$ de la base reguladora, sin que para los autónomos éste se rebaje al $60 \%$ a partir del día ciento ochenta y uno ${ }^{67}$. La cuantía, sin embargo, generalmente será sensiblemente menor, puesto que la base reguladora tiene como punto de referencia las bases de cotización del autónomo que, generalmente, suele elegir las mínimas ${ }^{68}$. En este sentido, volvemos a destacar que los problemas financieros del Sistema de Seguridad Social habrán determinado esta opción legislativa de mínimos para el autónomo, pues bien podría haberse incrementado este porcentaje.

La determinación de la cuantía máxima y mínima de esta prestación se realiza en idénticos términos que la prestación por desempleo, fijándose como un porcentaje sobre la cuantía del Indicador Público de Rentas de Efectos Múltiples ${ }^{69}$.

\section{BiBLIOGRAFÍA}

Alarcón Caracuel, Manuel Ramón - González Ortega, Santiago, Compendio de Seguridad Social (4a edición renovada, Madrid, Tecnos, 1991).

Alonso Soto, Las relaciones laborales en las cooperativas en España, en Revista de Derecho del Trabajo, 20 (octubre-diciembre de 1984).

Álvarez Alcolea, Manuel, La condición jurídico-laboral de los socios de las cooperativas de producción, en Revista de Politica Social, 10 (1975).

Álvarez del CuVillo, Antonio, El régimen profesional del trabajador autónomo económicamente dependiente, en CRUZ Villalón, Jesús - VAldÉs DAL RE, Fernando (directores), El Estatuto del Trabajo Autónomo (Madrid, La Ley, 2008).

Ballester Pastor, Inmaculada, El trabajador autónomo de la industria y de los servicios en el ordenamiento jurídico de la Seguridad Social, en Revista de Trabajo y Seguridad Social, 17 (1995).

Barrios Baudor, Guillermo - Sempere Navarro, Antonio, Régimen profesional

${ }^{67}$ Ley general de seguridad social, artículo 211.

${ }^{68} \mathrm{El}$ sistema de cotización de los trabajadores por cuenta propia se basa en el establecimiento legal de una base mínima y otra máxima de cotización, pudiendo elegir el autónomo su cuantía. Dado que, con la elección de la base mínima la cuota a ingresar ya resulta, de por sí, bastante elevada (alrededor de $240 €$ ), normalmente los autónomos optan por ella. Este sistema desconecta la cuantía de la obligación de cotizar con los ingresos reales obtenidos por el autónomo, lo cual está siendo objeto de críticas constantes por parte de la doctrina. Por todos: Cervilla Garzón, María José, La financiación de los regimenes especiales de trabajadores autónomos, en Temas Laborales, 81 (2005). Los asalariados, sin embargo, cotizan en función de la cuantía de su salario y, por ello, a mayor salario mayor será la posible cuantía de la prestación por desempleo.

${ }^{69} \mathrm{La}$ cuantía máxima será el $175 \%$ de dicho indicador, si no tiene hijos a cargo, y la mínima el $107 \%$. En caso de hijos a cargo, los porcentajes se incrementan al 200 o $225 \%$ y se reduce al $80 \%$. 
del trabajador autónomo económicamente dependiente, en AA. VV., Comentarios al Estatuto del Trabajo Autónomo (Pamplona, Aranzadi, 2010).

Canosa Rodrigo, Manuel, Campo de aplicación del Régimen Especial de la Seguridad Social de los Trabajadores del Mar, en Tribuna Social, 49 (1995).

Cervilla Garzón, María José, El esperado informe sobre la prestación por cese de actividad: análisis del ámbito subjetivo, hecho causante, dinámica, cuantía y diseño financiero, en Documentación Laboral, 87 (2009).

Cervilla Garzón, María José, La reforma "pro futuro" de la protección social de los trabajadores autónomos tras la aprobación de su nuevo Estatuto, en Actualidad Laboral, 19 (2008).

Cervilla Garzón, María José, La acción protectora de los trabajadores autónomos en el Sistema español de Seguridad Social (Sevilla, Mergablum, 2005).

Cervilla Garzón, María José, La financiación de los regímenes especiales de trabajadores autónomos, en Temas Laborales, 81 (2005).

Del Giudice, F. - Mariani, F. - Izzo, F., Diritto del lavoro (18 a ediciòn, Napoli, Edizioni Giuridiche Simone, 2000).

Desdentado Bonete, Aurelio - Tejerina Alonso, José Ignacio, La acción protectora del régimen especial de los trabajadores por cuenta propia o autónomos (Valladolid, Lex Nova, 2004).

Dueñas Herrero, El ámbito subjetivo de las cooperativas de trabajo asociado, en AA.VV., I Congreso de Castilla y León sobre Relaciones Laborales (Valladolid, Lex Nova, 1999).

González de Patto, Rosario, El nuevo régimen jurídico de las relaciones de trabajo en las cooperativas de trabajo asociado: ambivalencias en el proceso de laboralización del socio trabajador, en Temas Laborales, 53, (2000).

Gutiérrez Solar-Calvo, Beatriz - Lahera Forteza, Jesús, Ambito y fuentes de regulación del trabajo autónomo, en CRUZ Villalón, Jesús - VAldés Dal RE, Fernando (directores), El Estatuto del Trabajo Autónomo (Madrid, La Ley, 2008).

Javillier, Jean-Claude, Droit du Travail (2a edicion, Paris, Librairie Générale de Droit et Jurisprudence, 1981).

Jover Ramírez, Carmen, El informe sobre la protección por cese de actividad: promoción del trabajo autónomo, prestación y jubilación, gestión y régimen sancionador en Documentación Laboral, 87 (2009).

López Aniorte, María del Carmen, Ámbito subjetivo del Régimen Especial de Trabajadores Autónomos (Pamplona, Aranzadi, 1996).

López Gandía, Juan - TosCani Giménez, Daniel, El régimen profesional y de Seguridad Social de los Trabajadores Autónomos (Madrid, El Derecho, 2010).

Luján AlCARÁz, Juan, Las notas de laboralidad. Una aproximación en clave de jurisprudencia en Aranzadi Social, 16 (diciembre 2000).

Luján Alcaráz, Juan, El socio trabajador de las cooperativas de trabajo asociado en la L. 27/1999, de 16 de julio, de Cooperativas, en Aranzadi Social, 5 (1999).

Luján AlCARÁz, Juan, La contratación privada de servicios y el contrato de trabajo (Madrid, Ministerio de Trabajo y Seguridad Social, 1994).

Martín Valverde, Antonio, Trabajo asalariado y trabajo autónomo en el derecho comunitario europeo, en AA.VV. Trabajo subordinado y trabajo autónomo en la delimitación de fronteras del Derecho del Trabajo (Madrid, Tecnos, 1999).

Monereo Pérez, José Luis - Fernández Avilés, José Antonio, Los derechos de protección social de los trabajadores autónomos (Granada, Comares, 2009). 
Monereo Pérez, José Luis, La nueva fase del desarrollo del Pacto de Toledo: el acuerdo para la mejora y el desarrollo del Sistema de protección social, en Relaciones Laborales, 24 (diciembre de 2001).

Montoya Melgar, Alfredo, Sobre el socio-trabajador de la cooperativa de trabajo asociado, en AA. VV., Estudios de Derecho del Trabajo en memoria del Profesor Gaspar Bayón Chacón (Madrid, Tecnos, 1980).

Piñeyroa de la Fuente, Antonio, Invalidez provisional y trabajadores autónomos, en La Ley, 2 (1992).

Poquet Catala, Raquel, Protección por desempleo: el sistema tras las últimas reformas (Valencia, Tirant Lo Blanch, 2008).

Rodríguez Ramos, María José - Vilchez Porras, Maximiliano - Gorelli HerNÁNDEZ, Juan, Sistema de Seguridad Social (3a edición, Madrid, Tecnos, 2001).

SÁnChez-Uran AzaÑa, Yolanda, El desempleo de los trabajadores autónomos. Un estudio de la Ley 32/2010, de 5 de agosto, por la que se establece un sistema especifico de protección por cese de actividad de los trabajadores autónomos (Madrid, Thomsom Reuters, 2010).

Santiago Redondo, Koldo, Socio de cooperativa y relación laboral (Madrid, Ibídem, 1999).

VALDÉs DAL Re, Fernando, Las relaciones de trabajo en las cooperativas de trabajo asociado, en AA.VV., Primeros encuentros cooperativos de la Universidad del Pais Vasco (Vitoria-Gasteiz, Ediciones Gobierno Vasco, 1986). 